\title{
Comparison of the haemodynamic effects and seizure activity during modified ECT with thiopentone and propofol used as inducing agents.
}

\author{
Benhur Premendran ${ }^{1}$, Vijay Sharma ${ }^{2}$, Dr Earnestly ${ }^{3}$, Pradeep Dhande ${ }^{4}$, Sudha jain $^{5}$ \\ ${ }^{I} M D, M G I M S-S e v a g r a m-442102$ \\ ${ }^{2} D A, M D, D N B, M G I M S$-Sevagram-442102 \\ ${ }^{3} \mathrm{MD}$, MGIMS-Sevagram-442102 \\ ${ }^{4} \mathrm{MD}$, MGIMS-Sevagram-442102 \\ ${ }^{5} M D$, MGIMS-Sevagram-442102
}

\begin{abstract}
Electroconvulsive therapy is also known as Electroshock or Shock therapy or Electroplex. Seizure activity produced by ECT is considered as the therapeutic aspect of this form of treatment, but is accompanied by untoward physiologic consequences, mainly cardiovascular and cerebral in nature. The hemodynamic effects can have a significant impact in patients with underlying cardiovascular disease.The effects of certain anesthetic agents may render seizure activity difficult to generate,and the unmodified physiologic consequences of treatment may be harmful. At the present time, a number of medications have been used during ECT including pretreatment sedation, anaesthetic agents, muscle relaxants, anticholinergics, and drugs to attenuate parasympathetic and sympathetic responses. This single blinded study was carried out on 100 adult patients equally divided into two groups of 50 each to compare the Hemodynamic effects and seizure activity of thiopentone sodium (GroupT) and propofol(Group P) when used as inducing agents in patients undergoing modified electroconvulsive therapy (MECT). Results showed propofol maintained significantly better haemodynamics compared to thiopentone and seizure time was significantly lower with propofol compared to thiopentone with equal theurapeutic effect and comparable complication rate of MECT. Recovery from anaesthesia post MECT was significantly quicker with propofol compared with thiopentone. Hence,we conclude that from anaesthesiologist's point of view propofol has advantage over thiopentone when used as an induction agent for modified ECT due to its favorable haemodynamics and early recovery characteristics.
\end{abstract}

\section{Keywords: ECT, propofol, thiopentone}

\section{INTRODUCTION}

Electroconvulsive therapy is also known as Electroshock or Shock therapy or Electroplexy ${ }^{(1)}$. Electroconvulsive therapy (ECT) has changed substantially during the past decades. It has become more complex, more precise, and is always regarded as a highly sophisticated medical procedure ${ }^{(2)}$. It was introduced in clinical practice based on the finding that psychiatric symptoms are improved after seizure in patient suffering from both schizophrenia and epilepsy.Seizure activity produced by ECT is considered as the therapeutic aspect of this form of treatment, but is accompanied by untoward physiologic consequences, mainly cardiovascular responses and cerebral in nature ${ }^{(3)}$. The hemodynamic effects could have a significant impact in patients with underlying cardiovascular disease. The effects of certain anesthetic agents may render seizure activity difficult to generate, and the unmodified physiologic consequences of treatment may be harmful.During the few seconds following ECT stimulus there may be temporary drop in blood pressure. This may be followed by a marked increase in heart rate which may then lead to a rise in blood pressure.Upon awakening, a patient may experience a brief period of confusion, headache or muscle stiffness.Since no surgical procedure accompanies ECT, any morbidity or mortality is especially unfortunate, and may be consequent only to treatment or to the anaesthetic. Therefore the practicing anaesthesiologist must be prepared to manage these patients in a fashion that promotes effective seizure activity and simultaneously attenuates the physiologic effects of therapy ${ }^{(4)}$.

At the present time, a number of medications have been used during ECT including pretreatment sedation, anaesthetic agents, muscle relaxants, anticholinergics, and drugs to attenuate parasympathetic and sympathetic responses ${ }^{(6)}$. With the use of Succinylcholine by Wanderdel in 1951, modified ECTs came into existence. Use of general anaesthesia led to the reduced incidence of physical and psychological trauma. Since 
the 1960s, ECT under general anesthesia with quick-acting barbiturates has been used for the treatment of depression.The ideal intravenous anesthetic agents used for modified electroconvulsive therapy (MECT) should provide:rapid onset of action ${ }^{(6)}$, short duration of action $^{(5),}$ attenuation of the adverse physiological effects of ECT,rapid post-ictal recovery of consciousness ${ }^{(5)}$ and should not adversely shorten seizure time because of the probable beneficial relationship between total seizure and treatment efficacy ${ }^{(7)}$.

Due to non-availability of methohexitone, thiopentone sodium was being used till date for all MECTs despite of its side effects like prolonged awakening time, arrhythmias, laryngeal spasm and the hang over associated with its use is a definite disadvantage specially in psychiatric outpatient department where patients have to go back to their homes soon after the treatment.

Recently propofol has been recommended for ECT anaesthesia, because it is reported to provide more stable conditions as it has a rapid onset of action and better quality of recovery compared with barbiturate anaesthesia ${ }^{(8)}$. Considering all these aspects present study was designed to evaluate propofol as an induction agent for modified electroconvulsive therapy and compare it with thiopentone and the effect of these two agents on hemodynamic parameters and seizure duration.

\section{MATERIALS AND METHODS}

The present single blinded randomized controlled study was carried out in the department of Anaesthesiology, at MGIMS-Sevagram after approval of local institutional ethical committee. It compares the Hemodynamic effects and seizure activity of thiopentone sodium and propofol used as inducing agents in patients undergoing modified electroconvulsive therapy (MECT).

The study comprised of 100 psychiatric patients in the age group 15 to 60 years of either sex, ASA grades I and II are selected for the purpose of the study who were posted for Modified Electroconvulsive therapy. The patients were randomly divided in to two groups, group $\mathrm{T}$ and group $\mathrm{P}$ of 50 each. The patients will be randomized to receive either thiopentone (group T) or propofol (group P) as an inducing agent.

Our exclusion criteria included:

1. Patients refusal

2. Children below 15 years

3. Patients undergoing modified electroconvulsive therapy for the second time without any seizure on the previous ECT

4. ASA grade III and IV

5. Agitated patients requiring additional sedation

All patients underwent pre-anaesthetic evaluation comprising of history taking, clinical examination in either anaesthesia OPD or bed side in the psychiatry ward. Current medications were recorded and kept constant throughout the trial. Informed written consent was obtained from the patient and his responsible relatives or guardians and the procedure were fully explained to the patient and relatives in a clear, simple and vernacular language.

The procedure was carried out in the morning with all patients fasted overnight for at least 6 hours, were not using a dental prosthesis, contact lenses, or any ornaments, and were wearing proper clothing. The procedure room is fully equipped with drugs necessary for cardiopulmonary resuscitation, intubation and defibrillation. They were all adult patients; children and elderly were excluded from the study. The demographic data including age, body weight in $\mathrm{kg}$, and their ASA physical status were noted.

Investigations included haemogram, urine examination, chest $\mathrm{x}$-ray, ECG, blood urea, serum creatinine, serum electrolytes.

On arrival in the operation theatre, the intravenous line was set up using $18 \mathrm{G}$ cannula. The multipara monitor was connected to the patients. Monitoring of systolic blood pressure (SBP), diastolic blood pressure (DBP), heart rate (HR), electrocardiogram (ECG) and hemoglobin oxygen saturation $\left(\mathrm{SpO}_{2}\right)$ were observed and recorded prior to induction and throughout the procedure.

After starting intravenous line, all patients received pre-anaesthetic medications with inj. Glycopyrolate $0.2 \mathrm{mg}$ IV just before the start of the procedure. All patients were pre-oxygenated with $100 \%$ oxygen for 5 minutes. Anaesthesia was induced with either thiopentone (2.5\%) at the dose of $4 \mathrm{mg} / \mathrm{kg}$ or propofol(1\%) at the dose of $1.5 \mathrm{mg} / \mathrm{kg}$. The vital parameters were recorded again. The Blood pressure cuff is applied to the arm needed to be isolated from the effect of muscle relaxation, for observing localized seizures, is inflated 100 $\mathrm{mmHg}$ above systolic blood pressure and then succinylcholine was administered in the dose of $1 \mathrm{mg} / \mathrm{kg}$ body weight after isolating the arm by a blood pressure tourniquet.

All the patients were ventilated with 100\% oxygen with facemask using Magill's circuit (Mapleson A circuit) till fasciculation subsided and muscle relaxation was achieved.

A mouth gag (Roberto's mouth gag) was inserted inside the oral cavity separating tongue, teeth and buccal mucosa, to prevent any damage to the soft tissue of the oral cavity, tongue and fracture of teeth during 
the procedure. The electroconvulsive therapy was applied to the head through two electrodes kept at both sides of the temporo-frontal regions (bi-temporal ECT) after applying ECT gel on to the electrodes. Modified electroconvulsive therapy was given using a pulse of $60 \mathrm{~Hz}$ of $0.8 \mathrm{msec}$ duration with total stimulus time not exceeding 1.25 seconds, by BPE-591 machine, to all patients in the study. The mouth gag was changed to Guedel airway after the seizure activity subsided and patients were ventilated with $100 \%$ oxygen till regaining of spontaneous respiration.

The HR, SBP, DBP, $\mathrm{SpO}_{2}$ and ECG changes were recorded before induction of anaesthesia $\left(\mathrm{T}_{\mathrm{o}}\right)$, after administration of the study drug $\left(\mathrm{T}_{\mathrm{i}}\right)$, after succinylcholine $\left(\mathrm{T}_{\mathrm{s}}\right)$, after applying ECT $\left(\mathrm{T}_{\mathrm{e}}\right)$, at one minute $\left(\mathrm{T}_{1}\right)$, three minute $\left(T_{3}\right)$, five minute $\left(T_{5}\right)$, ten minute $\left(T_{10}\right)$ and at 15 minute $\left(T_{15}\right)$.

The duration of seizure activity was recorded in seconds by clinical method (tourniquet method) from the start of electrical impulse to the end of the clonic contraction using a hand held stopwatch.

The assessment of recovery was done on six criteria-

1. Establishment of spontaneous ventilation(R1)

2. When patient was able to open eyes on command(R2)

3. Able to answer the questions (like where are you) i.e. orientation(R3)

4. Able to sit up (R4)

5. Ability to stand(R5)

6. Ability to walk from the recovery $\operatorname{room}(\mathrm{R} 6)$

The assessment was done at frequent intervals and time noted from induction to achieve these criteria. Any incidence of pain on injection site, fall in oxygen saturation below 90\%, nausea, vomiting and cardiac arrhythmias were noted. Other side effects during induction, during the procedure and recovery are also noted like-

Induction:

- Discomfort on injection site, movement not due to light anaesthesia, hypertonus, hiccough, bronchospasm, flush, twitching, tremor, masseter spasm, cough, and laryngospasm.

During the procedure:

- Fracture of long bones, injuries to soft tissue of the oral cavity, laryngospasm, bronchospasm, cardiac arrest.

During recovery:

- Euphoria, withdrawal, headache, vomiting/nausea, bronchospasm, flush, depression, restlessness, confusion, amnesia, myalgia and laryngospasm.

To compare the study group, parametric data (like age, sex, weight) was analyzed by paired Student's ttest and non parametric data was compared by chi square test with Yates continuity correction. Data is presented as mean, unless otherwise stated. Figures in the brackets indicated the Standard Deviation. The level of statistical significance used was $\mathrm{p}<0.05$. The statistical analysis was done using programme STATA 12 special edition (Data analysis and statistical software) Texas, U.S.A.

\section{Observations and results:}

Table 1: Showing the mean pulse rate in both the groups

\begin{tabular}{|l|l|l|l|}
\hline TIME & GROUP T & GROUP P & $\begin{array}{l}\text { P } \\
\text { VALUE }\end{array}$ \\
\hline T0 & $83.16(12.65)$ & $81.42(13.60)$ & 0.50 \\
\hline T $_{\mathbf{i}}$ & $88.34(12.73)$ & $83.9(13.29)$ & 0.09 \\
\hline Ts & $86.54(12.03)$ & $82.68(13.16)$ & 0.12 \\
\hline Te & $92.72(11.30)$ & $86.06(12.69)$ & 0.006 \\
\hline T1 & $109.78(10.63)$ & $92.92(12.22)$ & 0.00 \\
\hline T3 & $116.94(11.34)$ & $97.32(11.74)$ & 0.00 \\
\hline T5 & $114.98(10.68)$ & $94.6(11.84)$ & 0.00 \\
\hline T10 & $112.4(10.71)$ & $89.0(11.86)$ & 0.00 \\
\hline T15 & $110(10.28)$ & $85.74(12.96)$ & 0.00 \\
\hline TOTAL & 50 & 50 & \\
\hline
\end{tabular}


Where, To= time before induction, Ti=at induction, $T s=j u s t$ after succinylcholine, Te $=$ just after the electrical stimulation was applied $(E C T), T 1=$ at 1 minute, $T 3=$ at 3 minute, $T 5=$ at 5 minute, $T 10=$ at 10 minute and T15= at 15 minute

Line diagram showing comparison of the mean pulse rate pre-procedure, during and after the procedure in both the groups

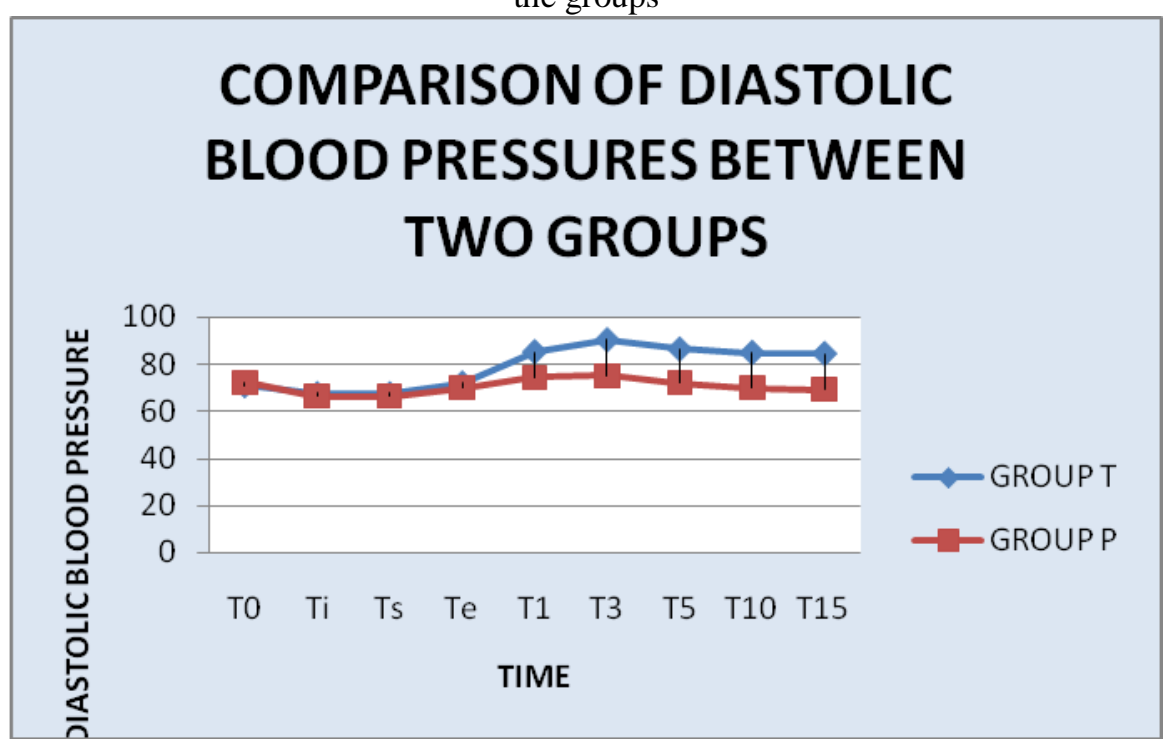

Table 2: Showing The Mean Systolic Blood Pressure In Both The Groups

\begin{tabular}{|l|l|l|l|}
\hline TIME & GROUP T & GROUP P & P VALUE \\
\hline T0 & $\begin{array}{l}114.08 \\
(13.27)\end{array}$ & $115.42(12.24)$ & 0.60 \\
\hline Ti & $\begin{array}{l}111.34 \\
(12.46)\end{array}$ & $106.7(10.44)$ & 0.04 \\
\hline Ts & $\begin{array}{l}111.37 \\
(13.13)\end{array}$ & $106.63(10.7)$ & 0.03 \\
\hline Te & $\begin{array}{l}125.47 \\
(12.9)\end{array}$ & $111.20(10.22)$ & 0.00 \\
\hline T1 & $\begin{array}{l}137.52 \\
(10.02)\end{array}$ & $114.38(9.92)$ & 0.00 \\
\hline T3 & $\begin{array}{l}142.04(9.3) \\
\text { T5 }\end{array}$ & $115.94(9.2)$ & 0.00 \\
\hline T10 & $\begin{array}{l}137.42(8.5) \\
(8.25)\end{array}$ & $112.8(9.3)$ & 0.00 \\
\hline T15 & $\begin{array}{l}131.28 \\
(15.65)\end{array}$ & $109.2(9.5)$ & 0.00 \\
\hline
\end{tabular}

Where, To= time before induction, Ti= at induction, $T s=$ just after succinylcholine, Te=just after the electrical stimulation was applied $(E C T), T 1=$ at 1 minute, $T 3=$ at 3 minute,T5= at 5 minute, $T 10=$ at 10 minute and T15= at 15 minute

Line diagram showing the comparison of mean systolic blood pressure pre-procedure, during and after the procedure in both the groups. 


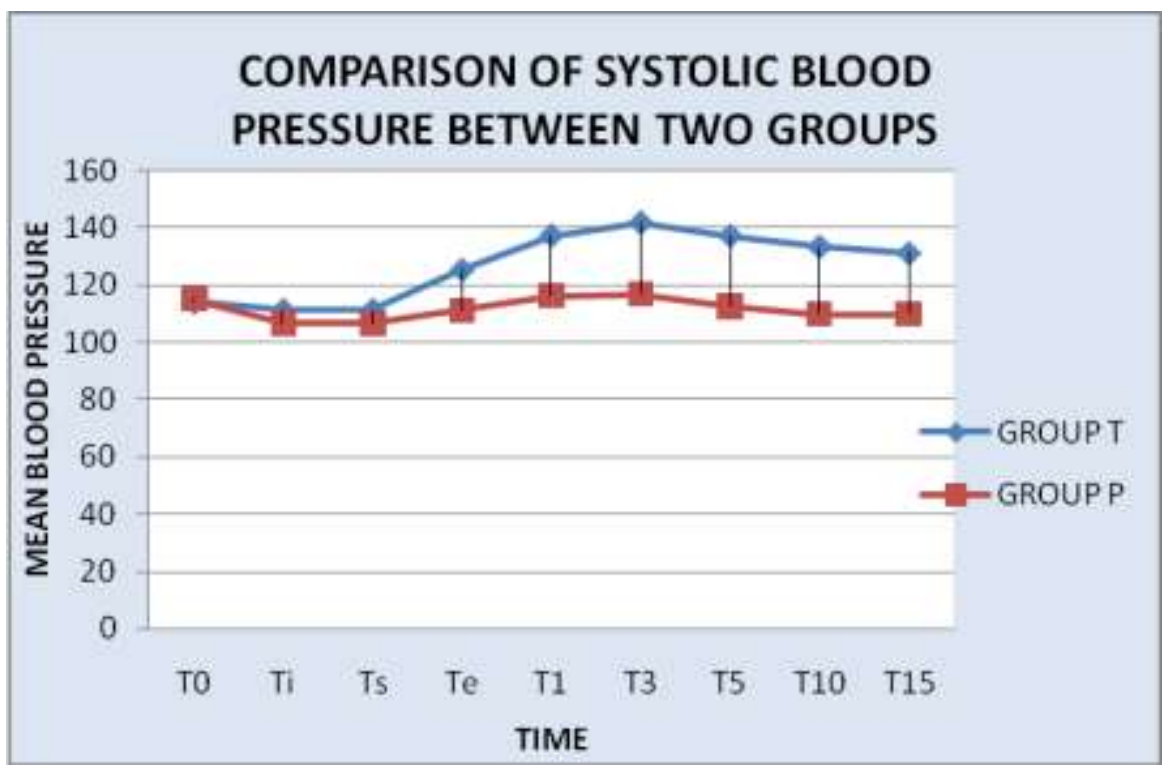

Table 3: Showing the mean diastolic blood pressure in both the groups:

\begin{tabular}{|l|l|l|l|}
\hline TIME & GROUP T & GROUP P & P VALUE \\
\hline T0 & $71.02(9.39)$ & $\begin{array}{l}72.22 \\
(10.58)\end{array}$ & 0.55 \\
\hline Ti & $67.6(8.99)$ & $66.46(9.3)$ & 0.53 \\
\hline Ts & $67.54(9.0)$ & $66.36(9.35)$ & 0.52 \\
\hline Te & $72.06(9.68)$ & $69.78(9.26)$ & 0.02 \\
\hline T1 & $\begin{array}{l}85.24 \\
(10.39)\end{array}$ & $74.24(9.45)$ & 0.00 \\
\hline T3 & $90.3(7.74)$ & $75.12(9.58)$ & 0.00 \\
\hline T5 & $86.42(7.55)$ & $72(9.18)$ & 0.00 \\
\hline T10 & $84.94(7.2)$ & $70.10(8.89)$ & 0.00 \\
\hline T15 & $84.52(7.08)$ & $69.28(8.69)$ & 0.00 \\
\hline
\end{tabular}

Where, To= time before induction, Ti= at induction, $T s=$ just after succinylcholine, Te $=$ just after the electrical stimulation was applied $(E C T), T 1=$ at 1 minute, $T 3=$ at 3 minute, $T 5=$ at 5 minute, $T 10=$ at 10 minute and T15= at 15 minute

Line diagram Showing comparison of the mean diastolic blood pressure pre-procedure, during and after the procedure in both the groups. 


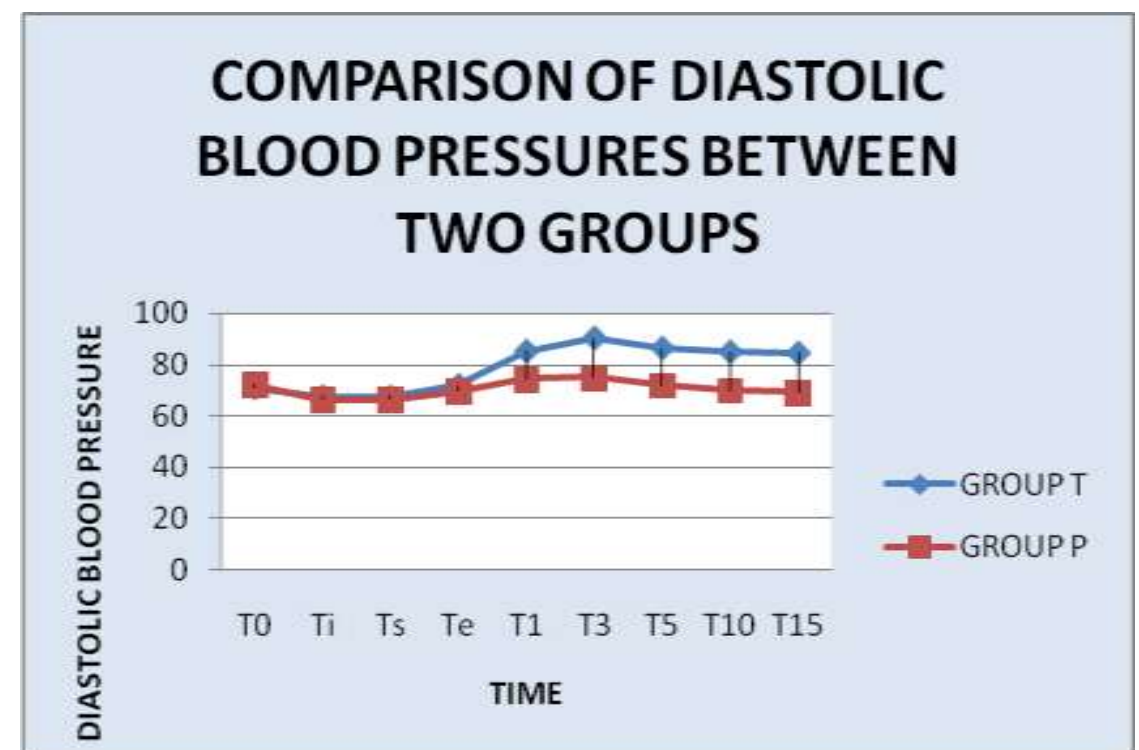

Table 4: Table showing the mean arterial blood pressure in both the groups:

\begin{tabular}{|l|l|l|l|}
\hline TIME & GROUP T & GROUP P & P VALUE \\
\hline T0 & $85.22(10.01)$ & $86.47(10.53)$ & 0.54 \\
\hline Ti & $82.03(9.58)$ & $79.73(9.11)$ & 0.22 \\
\hline Ts & $82.034(9.58)$ & $79.76(9.12)$ & 0.22 \\
\hline Te & $89.81(9.84)$ & $82.41(9.0)$ & 0.0001 \\
\hline T1 & $102.49(9.76)$ & $88.15(8.8)$ & 0.00 \\
\hline T3 & $107.37(7.71)$ & $88.89(8.69)$ & 0.00 \\
\hline T5 & $103.25(7.09)$ & $85.46(8.5)$ & 0.00 \\
\hline T10 & $100.98(6.75)$ & $83.17(8.54)$ & 0.00 \\
\hline T15 & $99.95(7.73)$ & $82.69(8.47)$ & 0.00 \\
\hline
\end{tabular}

Where, To= time before induction, Ti= at induction, $T s=$ just after succinylcholine, Te= just after the electrical stimulation was applied $(E C T), T 1=$ at 1 minute, $T 3=$ at 3 minute, $T 5=$ at 5 minute, $T 10=$ at 10 minute and T15= at 15 minute

Line diagram showing comparison of the mean arterial pressure between both groups 


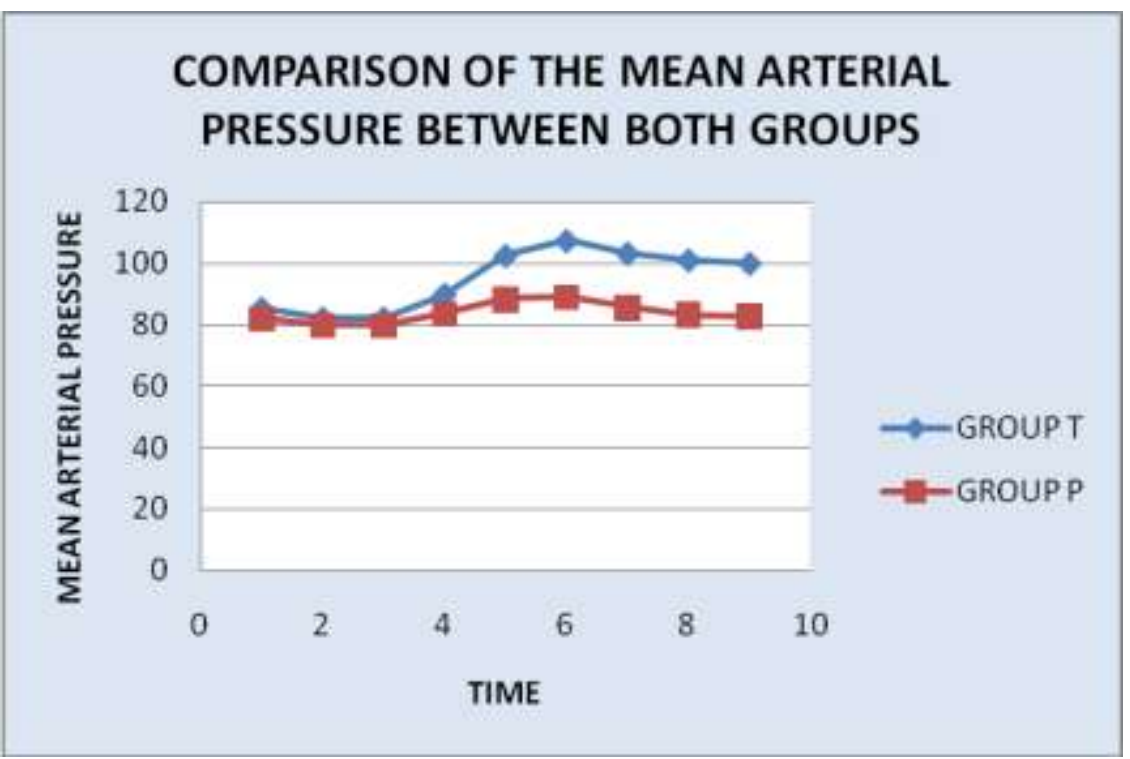

Table 5: Showing The Maximum Changes In The Hemodynamic Parameters

\begin{tabular}{|c|c|c|c|c|c|}
\hline & \multicolumn{2}{|l|}{ Group T } & \multicolumn{2}{|l|}{ Group P } & \multirow[b]{2}{*}{$\begin{array}{l}\text { p } \\
\text { value }\end{array}$} \\
\hline & $\begin{array}{l}\text { Actual } \\
\text { change }\end{array}$ & As \% & $\begin{array}{l}\text { Actual } \\
\text { change }\end{array}$ & As \% & \\
\hline $\begin{array}{l}\text { Maximum increase in } \\
\text { blood pystolic } \\
\text { baseline }(\mathrm{mmHg}) \\
\text { Mean for all patients }\end{array}$ & 27.96(3.93) & $24 \%$ & $0.52(3.03)$ & $0.5 \%$ & $<0.05$ \\
\hline 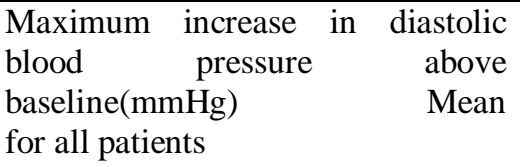 & $19.0(1.65)$ & $26 \%$ & $2.9(1.0)$ & $4 \%$ & $<0.05$ \\
\hline $\begin{array}{l}\text { Maximum increase in heart rate } \\
\text { above baseline(per minute). Mean } \\
\text { for all patients }\end{array}$ & $33.76(1.31)$ & $40 \%$ & $15.9(1.86)$ & $19 \%$ & $<0.05$ \\
\hline
\end{tabular}


Table 6: Showing ECG Changes During Electroconvulsive Therapy

\begin{tabular}{|c|c|c|c|c|}
\hline & \multicolumn{4}{|c|}{ Number of patients showing ECG changes } \\
\hline & Group T & $\%$ & Group P & $\%$ \\
\hline 1.No Disturbance & 17 & 34 & 25 & 50 \\
\hline 2.Sinus tachycardia & 21 & 42 & 16 & 32 \\
\hline 3.Sinus bradycardia & 1 & 2 & 0 & - \\
\hline 4. Ventricular ectopic beats & 3 & 6 & 2 & 4 \\
\hline 5.Atrial ectopic beats & 0 & - & 0 & - \\
\hline 6.Nodal premature beats & 0 & - & 0 & - \\
\hline 7.Supraventricular tachycardia & 0 & - & 0 & - \\
\hline 8.Minor ST-T changes & 8 & 16 & 7 & 14 \\
\hline 9.Heart block & 0 & - & 0 & - \\
\hline Total & 50 & & 50 & \\
\hline
\end{tabular}

Table 7: showing the mean seizure duration in both the groups:

\begin{tabular}{|l|l|l|l|}
\hline & GROUP T & GROUP P & P VALUE \\
\hline $\begin{array}{l}\text { SEIZURE } \\
\text { DURATION } \\
\text { (in seconds) }\end{array}$ & 28.42 & $22.56(4.66)$ & 0.00 \\
& $(6.44)$ & & \\
\hline
\end{tabular}

In comparison between the two groups, the $\mathrm{P}$ Value is $<0.05$

Bar diagram showing the mean seizure duration in both the groups 


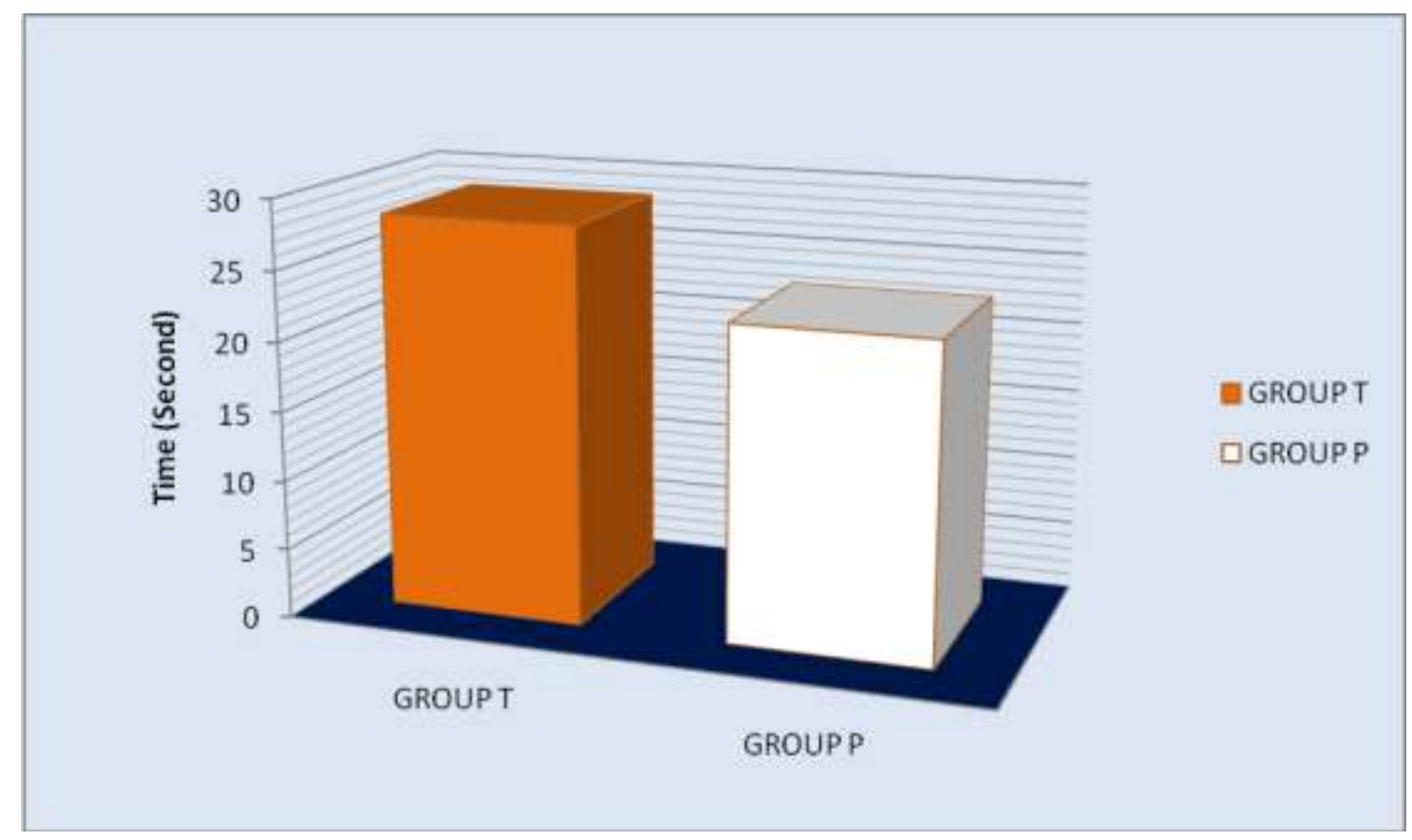

\begin{tabular}{|c|c|c|c|}
\hline RECOVERY & GROUP T & GROUP P & P VALUE \\
\hline $\begin{array}{l}\text { Establishment } \\
\text { spontaneous } \\
\text { ventilation(R1) }\end{array}$ & $3.66(0.649)$ & $3.248(0.58)$ & 0.001 \\
\hline $\begin{array}{l}\text { When patient was able } \\
\text { to open eyes on } \\
\text { command(R2) }\end{array}$ & $5.91(1.48)$ & $5.34(0.88)$ & 0.02 \\
\hline $\begin{array}{ll}\text { Able to answer } & \text { the } \\
\text { questions } & \text { i.e. } \\
\text { orientation(R3) } & \\
\end{array}$ & $8.56(2.12)$ & $7.56(1.46)$ & 0.005 \\
\hline Able to sit up (R4) & $11.95(2.45)$ & $9.79(2.05)$ & 0.00 \\
\hline Ability to stand(R5) & $15.98(1.83)$ & $13.22(2.85)$ & 0.00 \\
\hline $\begin{array}{l}\text { Ability to walk from the } \\
\text { recovery } \operatorname{room}(\mathrm{R} 6)\end{array}$ & $20.23(1.7)$ & $16.44(2.71)$ & 0.00 \\
\hline
\end{tabular}


Comparison of the haemodynamic effects and seizure activity during modified ECT with......

Table: 9 showing complications:

\begin{tabular}{|c|c|c|}
\hline COMPLICATIONS & GROUP T & GROUP P \\
\hline \multicolumn{3}{|l|}{ Induction } \\
\hline - Discomfort on injection site & 4 & 9 \\
\hline - $\quad$ Hypertonus & 0 & 0 \\
\hline - Hiccough & 1 & 0 \\
\hline - Bronchospasm & 0 & 0 \\
\hline - $\quad$ Flush & 0 & 0 \\
\hline - $\quad$ Twitching & 0 & 2 \\
\hline - $\quad$ Tremor & 0 & 0 \\
\hline - $\quad$ Masseter spasm & 0 & 0 \\
\hline - Cough & 1 & 0 \\
\hline - $\quad$ Laryngospasm & 0 & 0 \\
\hline \multicolumn{3}{|l|}{ During the procedure } \\
\hline - $\quad$ Fracture of long bones & 0 & 0 \\
\hline - Injuries to soft tissues of mouth & 0 & 0 \\
\hline - $\quad$ Laryngospasm & 0 & 0 \\
\hline - $\quad$ Bronchospasm & 0 & 0 \\
\hline - $\quad$ Masseter spasm & 0 & 0 \\
\hline - $\quad$ Cardiac arrest & 0 & 0 \\
\hline \multicolumn{3}{|l|}{ Recovery: } \\
\hline - $\quad$ Euphoria & 1 & 3 \\
\hline - Withdrawal & 0 & 0 \\
\hline - Headache & 1 & 1 \\
\hline - $\quad$ Backache & 0 & 0 \\
\hline - Vomiting & 0 & 0 \\
\hline - $\quad$ Nausea & 0 & 0 \\
\hline - Bronchospasm & 0 & 0 \\
\hline - $\quad$ Flush & 0 & 0 \\
\hline - Amnesia & 0 & 0 \\
\hline - $\quad$ Restlessness & 0 & 0 \\
\hline - Confusion & 2 & 1 \\
\hline - $\quad$ Laryngospasm & 0 & 0 \\
\hline - $\quad$ Myalgia & 0 & 0 \\
\hline - $\quad$ Agitation & 0 & 0 \\
\hline
\end{tabular}

III. ANALYSIS AND DISCUSSION

In our study, we compare the hemodynamic parameters, seizure duration and recovery in modified electroconvulsive therapy under general anaesthesia induced with either propofol or thiopentone. ECT is capable of provoking profound cardiovascular responses, the result of both the electroshock stimulus and the consequent seizure. As reported by well DG and Davies $\mathrm{GG}^{(3)}$, the convulsion itself was accompanied by 
Comparison of the haemodynamic effects and seizure activity during modified ECT with......

significant increases in heart rate (20\%), blood pressure (34\%) and cardiac output $(81 \%)$ when compared with pre anaesthesia values. The purpose of modifying ECT with anaesthesia is to prevent hypoxia, fractures, hypertension, arrhythmias, myocardial infarction and other complications. Anaesthesia attenuates but cannot completely eliminate cardiovascular and respiratory effects of ECT.

\section{Demographic profile}

In the present study 100 adult psychiatric patients of either sex with ASA grade I and II were enrolled, who were to undergo MECT. The patients belonging to both the groups were statistically comparable.

\section{Haemodynamic variability}

Before the procedure $\left(\mathrm{T}_{\mathrm{o}}\right)$ the mean pulse rate in group $\mathrm{T}$ was $83.16(12.65)$ and in group $\mathrm{P}$ was 81.42(13.60). The pulse rate in both the groups are comparable as the $\mathrm{p}$ value is $0.50(\mathrm{p}>0.05)$. At induction time $\left(\mathrm{T}_{\mathrm{i}}\right)$ the mean pulse rate was 88.34(12.73) in group $\mathrm{T}$ and 83.9(13.29) in group $\mathrm{P}$ which are again comparable, $\mathrm{p}$ value is $0.09(\mathrm{p}>0.05)$. After the muscle relaxant was given $\left(\mathrm{T}_{\mathrm{s}}\right)$ the mean pulse rate was 86.54(12.03) in group $\mathrm{T}$ and 82.68(13.16) in group $\mathrm{P}$ which are again comparable, $\mathrm{p}$ value being 0.12 ( $\mathrm{p}>0.05)$.

The difference between the mean pulse rates from the time when electrical stimulation was applied till recovery in both the groups were statistically significant $(\mathrm{p}<0.05)$. The mean heart rate as soon as after the electrical stimulation was applied $\left(\mathrm{T}_{\mathrm{e}}\right)$ and at $1^{\text {st }}, 3^{\text {rd }}, 5^{\text {th }}, 10^{\text {th }}$ and 15 minutes in group $\mathrm{T}$ was $92.72,109.78,116.94$, $114.98,112.4,110$ respectively which showed a significant increase in the mean pulse rate compared to the preinduction level. The maximum increase was seen at the $3^{\text {rd }}$ minute from the time of electrical stimulation. The mean heart rate as soon after the electrical stimulation was applied $\left(T_{e}\right)$ and at $1^{\text {st }}, 3^{\text {rd }}, 5^{\text {th }}, 10^{\text {th }}$ and 15 minutes in P group are 86.06, 92.92, 97.32, 94.6, 89.0 and 85.74 respectively. The maximum increased in heart rate was seen at the $3^{\text {rd }}$ minute from the stimulation. The mean heart rates of propofol group were not significantly increased when compared to the pre-induction level.

Investigators ${ }^{(9)}$ noticed increase in heart rate of about 20 to 30 beats per minute beginning with the clonic phase. Green and Woods ${ }^{(10)}$ also observed that marked tachycardia was usual. Both above studies correlate with our series where we have also observed that tachycardia is a common occurrence. Only one patient in our study had bradycardia $(\mathrm{HR}<50)$, belonging to group $\mathrm{T}$, which was corrected with $0.6 \mathrm{mg}$ IV atropine.The increases in the mean heart rate were significantly greater with group $\mathrm{T}$ using thiopentone sodium as the anaesthetic agent when compared to group $\mathrm{P}$ using propofol. The comparisons were statistically significant as the $\mathrm{p}$ value $<0.05$.

The mean maximum increases in heart rate after ECT was $40 \%$ for group $\mathrm{T}$ and $19 \%$ for group P.1Other workers have attributed this lower pulse rate with propofol to a resetting of baroreflexes to allow slower heart rates at lower arterial pressure ${ }^{(11)}$. The reduction in heart rate with propofol may have a favorable effect on myocardial oxygen demand. Rouse ${ }^{(12)}$ administered propofol $2 \mathrm{mg} / \mathrm{kg}$ after pretreatment with promethazine and atropine. This larger dose of propofol produced no greater reduction of the rise in systolic blood pressure than our study (reaching $3 \mathrm{mmHg}$ below the baseline value). Dwyer et al ${ }^{(13)}$ administered propofol $1.51 \mathrm{mg} / \mathrm{kg}$ and, in a single post seizure measurement, found that systolic pressure rose by $20 \mathrm{mmHg}$ or more only in $10 \%$ of patients, compared to in $30 \%$ of patients who received $1.19 \mathrm{mg} / \mathrm{kg}$ methohexital.

The mean arterial systolic pressure in group $\mathrm{T}$ was 114.08 and $115.42 \mathrm{mmHg}$ in group P. The two groups were comparable in their values before the procedure, $(\mathrm{p}>0.05)$. At induction time(Ti) the mean systolic pressure in group $T$ was 111.34 and group $P$ was 106.7 and the difference was statistically significant, $(p<0.05)$. As soon after the electrical stimulation(Te) was applied and at $1^{\text {st }}, 3^{\text {rd }}, 5^{\text {th }}, 10^{\text {th }}$ and $15^{\text {th }}$ minute intervals the mean systolic pressures recorded in group $\mathrm{T}$ were 125.47, 137.52, $142.04,137.42,133.56,131.28 \mathrm{mmHg}$ whereas in group $\mathrm{P}$ were $111.20,114.38,115.94,112.8,109.2,109.92 \mathrm{mmHg}$ respectively. The statistical differences between the two groups at these intervals were statistically significant, $(p<0.05)$.

The mean diastolic pressure before the procedure (To) in group T was 71.02 and in group $\mathrm{P}$ was 72.22 $\mathrm{mmHg}$ with $\mathrm{p}=0.55$. Thus both groups were statistically comparable ( $>0.05$ ). Again just after induction (Ti) and muscle relaxation (Ts) was given the mean diastolic blood pressure in group T was 67.6 and 67.54 and in group P it was 66.46 and 66.36 respectively, with p value 0.52 hence the difference was statistically comparable. But after the ECT $(\mathrm{Te}), 1^{\text {st }}, 3^{\text {rd }}, 5^{\text {th }}, 10^{\text {th }}, 15^{\text {th }}$ minute interval the mean diastolic blood pressure in group $\mathrm{T}$ and group P were 72.06, 85.24, 90.3, 86.42, 84.94, 84.52 and $69.78,74.24,75.12,72.0,70.10,69.28$ respectively. The difference was statistically significant with $\mathrm{p}$ values $<0.05$.

The mean arterial pressure (MAP) before the procedure (To) in group $\mathrm{T}$ was 85.22 whereas in group $\mathrm{P}$ it was $86.47 \mathrm{mmHg}$ which were statistically comparable (p>0.05). Just after induction(Ti) and muscle relaxation(Ts) the mean MAP in group T was 82.03 and 82.034 and the mean MAP in group P was 79.73 and $79.76 \mathrm{mmHg}$ which was again statistically comparable, $(\mathrm{P}>0.05)$. After the ECT $(\mathrm{Te}), 1^{\text {st }}, 3^{\text {rd }}, 5^{\text {th }}, 10^{\text {th }}, 15^{\text {th }}$ minute the mean MAP in group T and group P was 89.81, 102.49, 107.37, 103.25, 100.98, 99.95 and 82.41, $88.15,88.89,85.46,83.17,82.69$ respectively. The differences between the two groups were statistically significant. $(\mathrm{p}<0.05)$. 
There was a significant fall in mean systolic blood pressure immediately after induction by $7.5 \%$ from 115.45 to 106.7 in group P as compared to $2.4 \%$ from 114.08 to 111.34 in group T. The fall of blood pressure in group $\mathrm{P}$ has been advantageous to attenuate the severe disturbances in the transient period of hypertension during electroconvulsive therapy. None of the patients in either group exhibited any hypotension.

Investigators ${ }^{(9)}$ observed increase in systolic blood pressure of about 50 to $60 \mathrm{mmHg}$. In some patients the blood pressure reaches a peak within 60 secs and then returns to normal, although in some it continues to rise for three minutes. In our series, the group $\mathrm{P}$ using propofol as inducing agent, the mean maximum rise in systolic pressure above the baseline figure after the electrical stimulation was only $0.5 \mathrm{mmHg}$, significantly less than the value of $27 \mathrm{mmHg}$ with group $\mathrm{T}$ using thiopentone .The mean maximum rise in diastolic pressure above the baseline was $3 \mathrm{mmHg}$ in group $\mathrm{P}$ and $19 \mathrm{mmHg}$ in group $\mathrm{T}$.

The hemodynamic changes during ECT involve sequential increases in parasympathetic and sympathetic nervous system activity and a sudden elevation of catecholamines in the circulatory system is observed, causing a short but significant increase in heart rate and blood pressure ${ }^{(5)}$. Maximal changes in blood pressure and heart rate correspond to approximately a 15 fold increase in plasma adrenaline and a 3 fold increase in noradrenaline in a study by Jones and $\mathrm{Knight}^{(14)}$. A correlation has been established between rise of systolic blood pressure and circulating noradrenaline level which remain elevated even 10 minutes after the procedure. The use of a combination of vagolytic and beta adrenergic blocking drugs to blunt the cardiovascular effects of electroconvulsive therapy is well accepted. In addition, the anaesthetic agents used during electroconvulsive therapy has an important impact on the hemodynamic response.

The increase in mean arterial blood pressure and heart rate were significantly greater in group $\mathrm{T}$ with thiopentone as the anaesthetic agent and lower with propofol group.Analysis of the data suggested that propofol provides the best protection against an untoward hypertensive response to ECT, while thiopentone was less effective in blunting the hyperdynamic response. Severe elevations in the blood pressure and heart rate may be hazardous, and indeed, the commonest causes of mortality following ECT are myocardial infarction and ventricular dysrhthmias.

Previous studies of the hemodynamic effects of propofol have found a consistent reduction in systemic arterial pressure ${ }^{(15)}$ and we postulated that this property might be used to provide adequate attenuation of the hypertensive response to ECT. The findings of our study support this premise. Propofol consistently reduced the systolic arterial pressure to the extent that the mean maximum rise was only $0.5 \%$ above the baseline figure, while, with thiopentone, the mean rise was $24 \%$ after the electrical convulsion. This pharmacological effect of propofol which immediately decreases heart rate and blood pressure when administered as induction agent is advantageous for ECT patients as severe physiological disturbance in the above parameters are undesirable but mostly unavoidable by thiopentone induction.

In previous studies we also found stable systemic hemodynamic during ECT using propofol compared with thiopentone. Others have compared the effects of propofol, thiopentone or methohexitone on hemodynamic during electroconvulsive therapy ${ }^{(8)}$. Boey and $\mathrm{Lai}^{(8)}$ examined the comparative effects of propofol versus thiopentone and reported that the increases in systolic and diastolic BP and heart rate after ECT were significantly higher with thiopentone.

\section{Changes in ECG}

Electroconvulsive therapy has been advocated as the antidepressant therapy of choice in cardiac patients because of the cardiotoxic effects of psychotropic drugs ${ }^{(16)}$, however electrocardiographic changes have been reported with $\mathrm{ECT}^{(17)}$. The baseline ECGs of all the patients in two groups were within normal limits; the changes during ECT are shown in Table 13.Most common effect was sinus tachycardia which is seen in 21 $(42 \%)$ in group T and $16(32 \%)$ in group P. Minor ST-T changes were seen in 8(16\%) patient in group T and $7(14 \%)$ in group P. $3(6 \%)$ patients in group T and $2(4 \%)$ patients in group P developed ventricular ectopic beats. $1(2 \%)$ patient in group T developed sinus bradycardia. Thus $11(22 \%)$ patients in group $\mathrm{T}$ and $9(18 \%)$ patients in group P developed arrhythmias. Whether the T-waves abnormalities represent cardiac ischemia is controversial ${ }^{(17)}$, but their incidence is higher in patients with preexisting cardiac disease.

Dysrhythmias seen during ECT are result from the predominance of either parasympathetic or sympathetic activity, modified by other factors such as amount of current delivered, anaesthetic technique and concurrent drug therapy ${ }^{(18)}$. There was no evidence of any supraventricular tachycardia, heart block or junctional rhythm in the study. Supraventricular premature beats were not observed in this study but were reported by Lewis and Richardson ${ }^{(19)}$ and Green and Woods ${ }^{(11)}$. Two cases of supraventricular tachycardia were observed by D. Dasgupta and Vinita A Galanikar ${ }^{(20)}$. Gupta and colleague in his studies he found that the incidence of arrhythmias with thiopentone was $8 \%$ while no cardiac irregularities were observed with the use of etomidate ${ }^{(21)}$. Bankhead et $\mathrm{al}^{(22)}$ pointed out that ECT may result in death because of adverse effects on initiation and conduction of cardiac impulse. 
Overall, there was no significant difference between the incidence of dysrhythmias observed with the two agents. The dysrhythmias that did occur were all of transient nature, and most had resolved spontaneously by 1 minute after the administration of the ECT and no intervention was needed.

\section{Oxygen saturation:}

The mean oxygen saturation before the procedure, during the electroconvulsive therapy and during recovery periods did not drop below $96 \%$ in both the groups measured by the pulse oximeter. All the patients were ventilated with $100 \% \mathrm{O}_{2}$ throughout the procedure. As reported by Dasgupta et al ${ }^{(2)}$ ventilation with $100 \%$ $\mathrm{O}_{2}$ can prolong seizure duration and improve the therapeutic efficacy of MECT.

\section{Seizure duration:}

The aim of electroconvulsive therapy is to obtain generalized convulsions over 20 seconds. Although there is no beneficial effect with only one seizure, clinical improvement can be observed with a total seizure time over 210 seconds $^{(7)}$. Because the seizure is the therapeutic agent, the duration of seizure discharge is the significant variable of therapeutic efficacy. Reducing the duration of convulsive activity in the brain reduces the therapeutic efficacy.

The duration of seizures during ECT is influenced by many factors, including the method of oxygenation, type of electrical stimulus, age of the patient, blood gas tensions, number of previous treatments, concurrent drug therapy and technique used for measurement. The choice and dose of an anaesthetic agents used for induction can also affect the seizure duration and hence the efficacy of the electroconvulsive therapy.Since our study was within patient comparison, it is probable that the oxygen and carbon dioxide tensions were similar with both induction agents. It is disputed whether seizure duration increases or decreases as a course of ECT progresses $^{(7)}$. The seizure duration was significantly longer when patients were ventilated with oxygen and this considered a favorable feature for the therapeutic efficacy of $\mathrm{ECT}^{(20)}$.

The mean seizure duration in group $\mathrm{T}$ was 28.42(6.44) sec and 22.56(4.66) sec in group $\mathrm{P}$, a reduction of $7 \%$. The mean seizure duration in both the groups were statistically significant as the $p$ value is $0.00(p<0.05)$ .Seizure duration can be measured by several techniques: clinical observation of clonic movements in the isolated forearm, recording of the electromyogram, or electroencephalogram. It would appear from several studies comparing different measurement techniques that, when a seizure has obviously occurred, simple clinical observation is usually quite adequate for estimation of seizure duration, giving values slightly shorter than EEG seizure duration ${ }^{(7)}$ with little advantage in using an isolated forearm. However, in cases where there is poor clinical evidence of a seizure, EEG monitoring is more useful. In our study, we used a clinical observation of clonic movements in the isolated forearm using stopwatch.

The effect of propofol on seizure activity is not clear .Glen et $\mathrm{al}^{(23)}$ found that convulsion in mice after electric shock was not affected by propofol. Recent case reports have suggested a possible relationship of propofol to seizure and ophisthotonus ${ }^{(24)}$. While there have been two reports of successful treatment of uncontrollable status epilepticus with propofol. Studies that compare propofol and methohexitone for ECT have shown a shorter duration of seizure with propofol ${ }^{(12)}$, W. Boey and F.O. Lai also found a similar effect in this study with propofol compared to thiopentone in both treatments ${ }^{(8)}$. It has generally been considered that the duration of seizure is important for the therapeutic efficacy of ECT, with a minimum desirable seizure duration was considered as $25 \mathrm{~s}$ during ECT by Fink ${ }^{(25)}$ but recent work has questioned this.

Our mean seizure duration was 22.56 seconds with propofol compared to 37.5 seconds reported by W. Boey and F.O. Lai ${ }^{(8)}, 23.9$ seconds reported by Dwyer et al ${ }^{(13)}$ and 18.0 seconds by Rouse and colleagues ${ }^{(12)}$. Simpson et $\mathrm{al}^{(26)}$ reported seizure duration as a median of 19.0 seconds. Comparison of the duration of seizure of electroconvulsive therapy between these studies is difficult because of differences in the dose of propofol used, the method of ventilation before ECT, since hyperventilation prolongs seizure and the different methods of measuring duration of seizure.In our study, the shorter seizure times were obtained with propofol group when compared to thiopentone group. This results is in agreement with results in the literature ${ }^{(8)}$ that show significant reduction in seizure duration with propofol, without affecting MECT efficacy or therapeutic outcome ${ }^{(8)}$.

\section{Recovery profile:}

The mean recovery time taken by the patients to established a spontaneous ventilation (R1) in group T was $3.66(0.649)$ minutes compare to $3.25(0.58)$ minutes in group P. The group were statistically significant, $\mathrm{p}=0.001(\mathrm{p}<0.05)$. The ability of the patient to open eyes on command (R2) was established at 5.91(1.48) minutes in group T compare to 5.34 (0.88) minutes in group P. Again the group were statistically significant, $\mathrm{p}=0.02(\mathrm{p}<0.05)$.

In group $\mathrm{T}$, the mean time taken by the patients to answer question i.e. orientation (R3), able to sit up (R4), able to stand (R5) and able to walk (R6) were 8.56, 11.95, 15.98, 20.23 minutes respectively. While in group P, the mean time taken by the patients to answer question i.e. orientation (R3), able to sit up (R4), able to stand (R5) and able to walk (R6) were 7.56, 9.79, 13.22, 16.44 minutes respectively. The groups were 
statistically significant as the $\mathrm{p}$ value being $<0.05$. Recovery time was measured from the time as soon as the electrical stimulation was applied.

In our study, it showed that group P using propofol as an inducing agent had significantly earlier recovery $(\mathrm{P}<0.05)$ when compared to group $\mathrm{T}$ using thiopentone. The complex psychomotor tests were not used for recovery assessment from anaesthesia. Simple recovery test like ability of the patients response to vocal commands with opening eyes, able to answer question, ability to sit unaided, stand and walk from the recovery room were used and the recovery profile showed a significant $(\mathrm{p}<0.05)$ decrease in the recovery time in group $\mathrm{P}$ when compared to group T.

The ability of the patients to walk 20 minutes after induction was significantly better in group P using propofol. This is important not only for day patients who go home after the procedure, but also for the inpatients that are usually discharged early from the recovery area to their respective wards. Shortening of the recovery time can save lot of valuable time of the anaesthesiologist without compromising safety of the patients. In the study done by Bilge and colleague ${ }^{(27)}$, they found that propofol administered patients, oral response to oral stimulation times were observed to be shorter with regard to the other agents.

\section{COMPLICATIONS:}

The brevity and benign nature of cardiovascular disturbances makes ECT a safe procedure for healthy patients. Even in patients with cardiac complications under control like hypertension, angina, old infarction, heart failure and arrhythmias ${ }^{(19)}$, ECT remains essentially a safe procedure as long as decompensating factors like excessive sympathetic stimulation, hypoxia, hypercapnia, acidosis and electrolyte disturbance are avoided. Profound increase in cerebral blood flow and rise in intracranial pressure makes ECT dangerous in patients with pre-existing elevated intracranial pressure due to space occupying lesions ${ }^{(28)}$.

During ECT, complications can occur at any stage during induction, during the application of electric current or recovery. In our study, during induction, some patients complained of severe injection pain, but this problem was solved by slower injection and the use of larger veins. Out of 100 patients, $14 \%$ of patients in group P and $10 \%$ of patients in group $\mathrm{T}$ complained of pain and discomfort at the injection site. We did not encounter any bronchospasm/ laryngospasm, myoclonus or any increased tonus-related complications. However 1 patient had hiccough and 1 patient had cough in group $\mathrm{T}$ and 2 patients had twitching in group $\mathrm{P}$.

During the procedure there was no ECT related complications like fracture of long bones, vertebrae, injuries to the soft tissue of the mouth, tongue. In the series of Alexander et $\mathrm{al}^{(29)}, 5$ out 5325 patients were fatal. He pointed out that cardiovascular complications are most dangerous and are due to acute heart failure, vascular collapse, pulmonary edema and disturbance of cardiac rhythm. Thirty five cardiac arrests during ECT were reported in California during the period 1974-1983 and cardiovascular mortality remains as high as $0.03 \%$. Arnerson and Butler (1961) and Alexander (1964) reported death after ECT due to cardiac arrest and coronary occlusion respectively. They consider that sudden vagal stimulation during ECT is a potential factor in cardiac arrest and atleast $2 \mathrm{mg}$ of atropine sulphate must be given to combat this. In our small series there was no case of cardiac arrest or dead.

Gerring and Shields ${ }^{(30)}$ reported one death in a series of 42 patients. They identified a group of patients at high risk for the development of myocardial ischemia and/or arrhythmias following ECT. This group was comprised of patients with a history of angina, myocardial infarction, congestive heart failure, arrhythmias, rheumatic heart disease, or a baseline abnormal ECG. The Cardiovascular complication rate in this group was $70 \%$.

In the recovery period, complications such as headache, backache, dizziness, emesis and cough, withdrawal, euphoria, depression, confusion can be observed. In our study as shown in table 16, 1 patient in group $\mathrm{T}$ and 2 patients in group $\mathrm{P}$ developed euphoria. 3 patients in group $\mathrm{T}$ and 1 patient in group $\mathrm{P}$ had headache. 1 patient developed confusion in group T. Cough, which is probably due to increased secretions, can be overcome by the use of glycopyrolate. In a study done by Gupta and his colleague about $26 \%$ patients with thiopentone showed post ECT drowsiness, $12 \%$ had nausea and vomiting $\left({ }^{21)}\right.$.

In view of the data provided, we conclude that patients undergoing ECT should be evaluated by an anesthesiologist before treatment. Consultation with a psychiatrist would also be useful in increasing the effectiveness of the treatment and reducing the probable complications.

The administering of ECT is an unusual situation for the anesthesiologist, as it is not performed in the operating theater. Anaesthesiologist should be prepared for any emergency situation that might occur during ECT. Anaesthesia that is applied during ECT should aim to reduce seizure-related complications and obtain a short recovery period by use of quick-acting drugs which do not interfere much with seizure times.

\section{BIBLIOGRAPHY}

[1]. Narayan VB, Jain MK. Anaesthetic management for electroconvulsive therapy. J Anaesth Clin Pharmacol 2008;24(3):259-76.

[2]. Chanpattana W. Anaesthesia for Electroconvulsive therapy. German J Psychiatry 2001;4:33-9. 
[3]. Wells DG, Davies GG. Hemodynamic changes associated with electroconvulsive therapy. Anesth Analg 1987;66:1193-5..

[4]. Gaines GY, Rees I. Anaesthetic Considerations for Electroconvulsive Therapy. Southern Medical Journal 1992;85(5):469-82.

[5]. Gaines GY, Rees I. Electroconvulsive therapy and Anaesthetic considerations. Anaesth Analg 1986;65:1345-56.

[6]. APA. The practice of ECT: Recommendation for treatment, training and privileging. American Psychiatric press 2001:125-39.

[7]. Maletzky BM. Seizure duration and clinical effect in electroconvulsive therapy. Compr Psychiatry 1978;19:541-50.

[8]. Boey WK, Lai FO. Comparison of propofol and thiopentone as anaesthetic agents for electroconvulsive therapy. Anaesthesia 1990;45:623-8.

[9]. Shah VD, Mansuri AM, Hakim IR et al. Cardiovascular and electrocardiographic changes after electroconvulsive therapy- A series of 50 cases. Indian Journal of psychiatry 1977;19(4):51-3.

[10]. Green R, Woods A. Effects of modified ECT on the electrocardiogram. Br Med J 1955;1:1503.

[11]. Claeys MA, Gepts E, Camu F. Hemodynamic changes during anaesthesia induced with and maintained with propofol. Br J Anaesth 1983;60:3-9.

[12]. Rouse E. Propofol for ECT: A comparison with methohexitone. Premilinary report. Anaesthesia 1988;43:61-4.

[13]. Dwyer R, McCaughey W, Lavery J et al. Comparison of propofol and methohexitone as anaesthetic agents for ECT. . Anaesthesia 1988;43:459-62.

[14]. Jones R, Knight P. Cardiovascular and harmonal responses to electroconvulsive therapy. Anaesthesia 1981;36:795.

[15]. Grounds RM, Twigley AJ, Carli F. The hemodynamic effects of intravenous induction. Anaesthesia 1985;40:735-40.

[16]. Dec DW, Stem TA, Welch C. The effect of electroconvulsive therapy on serial electrocardiograms and serum cardiac enzymes values. JAMA 1985;253:2525-9.

[17]. Khoury G, Benedetti C. T-waves changes associated with electroconvulsive therapy. Anaesth Analg 1986;69:677-9.

[18]. McKenna G, Engle RP, Brooks H, Dalen J. Cardiac arrhythmias during electric shock therapy: significance, prevention and treatment. Am J Psychiatry 1970;127:530-3.

[19]. Lewis W, Richardson D. Cardiovascular disturbances and their management in modified electrotherapy for psychiatric illness. The New Engl J Med 1955;252:1016.

[20]. Dasgupta D, Galanikar VA. Cardiorespiratory changes during modified electroconvulsive therapy. Ind J of Anaesth 1991;39:98104.

[21]. Gupta UK, Mahendru RK, Mehta RK, Sonkar P. A comparative study of etomidate and thiopentone in modified ECT. Indian Journal of psychiatry 1986;28(2):151-4.

[22]. Bankhead AJ, Torrens JK, Harris TH. The anticipation and prevention of cardiac complication in ECT. Am J Psychiatry 1950;106:911-7.

[23]. Glen JB, Hunter SC, Blackburn TP, Wood P. Interaction studies and other investigations of the pharmacology of propofol (Diprivan). Postgrad Med J 1985;61:7-14.

[24]. Victoria RAP, Magee D. A case of convulsion after propofol anaesthesia. Anaesthesia 1988;43:904.

[25]. Fink M. Convulsive therapy: theory and practice. New York, Raven Press 1979.

[26]. Simpson KH, Halsall PJ, Carr CME, Steward KG. Propofol reduces seizure duration in patients having anaesthesia for electroconvulsive therapy. Br J Anaesth 1988;61:343-4.

[27]. Bilge Cerebioglu, Halide Yigit, Murat Rezaki et al. Anaesthesia in electroconvulsive therapy. Annals of Saudi Medicine 1999;19(2):144-6.

[28]. Posner J, Plum F. Cerebral metabolism during electrically induced seizure in man. Arch Neurol 1969;20(1):388.

[29]. Alexander SP, Orangeburg NV, Lawrence et al. Death following electrotherapy. JAMA 1956;161:577.

[30]. Gerring JP, Shields HM. The identification and management of patients with a high risk for cardiac arrythmias during modified ECT. J Clin Psychiatry 1982;42:1403-6. 